\title{
Analysis and Prognosis of Failures in Intelligent Hybrid Systems Using
} Bioengineering: Gear Coupling

\section{Análise e Prognose de Falhas em Sistemas Hibridos Inteligentes Utilizando}

\section{Bioengenharia: Acoplamento de Engrenagens}

Article Info:

Article history: Received 2021-11-13 / Accepted 2021-12-20 / Available online 2022-01-12 doi: 10.18540/jcecvl8iss1pp13673-01-18e

Roberto Outa

ORCID: https://orcid.org/0000-0002-8649-1722 Faculdade de Tecnologia de Araçatuba - Faculdade de Tecnologia de Lins, Brazil

E-mail: roberto.outa@fatec.sp.gov.br

Fabio Roberto Chavarette

ORCID: https://orcid.org/0000-0001-5376-3392

UNESP - Univ. Estadual Paulista, Brazil

E-mail: fabio.chavarette@unesp.br

Vishnu Narayan Mishra

ORCID: https://orcid.org/0000-0002-2159-7710

Department of Mathematics, Indira Gandhi National Tribal University, Madhya Pradesh, India

Email: vnm@igntu.ac.in.

Aparecido Carlos Gonçalves

ORCID: https://orcid.org/0000-0001-5376-3392 UNESP - Univ. Estadual Paulista - Faculdade de Engenharia de Ilha Solteira, Brazil

E-mail: aparecido.carlos@unesp.br

Adriana Garcia

ORCID: https://orcid.org/0000-0003-3054-1804

Institute of Technological Research of the State of São Paulo S.A - IPT, Brazil

E-mail: adrianag@ipt.br

Sandro da Silva Pinto

ORCID: https://orcid.org/0000-0002-1484-8534

Faculdade de Tecnologia de Lins, Brazil

E-mail: sandro.pinto@ fateclins.edu.br

Laxmi Rathour

ORCID: https://orcid.org/0000-0002-2659-7568

Ward number - 16, Bhagatbandh, Anuppur 484 224, Madhya Pradesh, India

E-mail: laxmirathour817@gmail.com

Lakshmi Narayan Mishra

ORCID: https://orcid.org/0000-0001-7774-7290

Department of Mathematics, School of Advanced Sciences, VIT University, Tamil Nadu, India

E-mail: lakshminarayanmishra04@gmail.com

\section{Resumo}

Este trabalho é de conceito multidisciplinar, cujo desenvolvimento é de difícil performance. Considerando ainda que, em uma das etapas é demonstrado a similaridade entre as FRF do sinal de vibração e acústica. O objetivo deste trabalho é a análise e prognose da progressão das falhas de um par de engrenagens utilizando o sistema imunológico artificial (AIS) de seleção negativa. Para que esta condição tenha sido atendida, durante o desenvolvimento deste trabalho, foram aplicados a técnica de filtro de Wiener, a análise de sinais (FRF) de vibração e acústica, a aplicação das técnicas 
de AIS de seleção negativa para classificação e grupamento dos sinais. O resultado final demonstra com sucesso a eficácia do processo de desenvolvimento deste trabalho e a robustez do algoritmo de AIS de seleção negativa.

Palavras-chave: Prognose. Sistemas Híbridos. Engrenagens.

\begin{abstract}
This work is of multidisciplinary concept, whose development is difficult to perform. Considering also that, in one of the steps, the similarity between the FRF of the vibration and acoustic signal is demonstrated. The objective of this work is the analysis and prognosis of the progression of failures of a pair of gears using the artificial immune system (AIS) of negative selection. In order to have this condition met, during the development of this work, the Wiener filter technique, the vibration and acoustic signal analysis (FRF), the application of negative selection AIS techniques for classification and grouping of signals were applied. The final result successfully demonstrates the effectiveness of the development process of this work and the robustness of the negative selection AIS algorithm.
\end{abstract}

Keywords: Prognosis. Hybrid Systems. Gears.

\title{
1. Introduction
}

Industry 4.0 represents several technologies and integrates them with the objective of promoting digitization in industries by improving processes and product quality. The technologies used in industry 4.0 are several, among them we can mention artificial intelligence, cyber-physical systems and internet of things (IoT) (Kagermann et al, 2013, Herman et al, 2016, Echeberria, 2020). Proposals such as the flexibilization of production, proposes a service to consumers promoting the reduction of costs of products, because the company tends to decrease supplies working with the essential to demand. With this, new production models and machines are linked to technology serving an increasingly competitive market, whose general expectation is that consumers avoid parts failures through maintenance schedules using the service strategy via IoT (Echeberria, 2020).

Failure diagnosis determines the analysis of behaviors such as: detection, isolation, identification and estimation of failures, and ensures the safety and reliability of a system in the industrial plant. This can be done by intelligent systems. Some components are equipped with intelligent sensors that can collect and process data evaluating their health status. If the fault is not detected it is possible that other components of the physical system will be affected, increasing the severity of the system (Borutzky, 2021). Therefore, it is necessary to understand the probable causes of failure, damage and failures of a machine. An example is the failures of the teeth of a gear are the result of various influences and, in many cases, through an early diagnosis it is possible to avoid major damage (Bloch, Geitner, 2012).

In recent decades, several efforts have been made to diagnose hybrid systems, but little is known of the reports of the predictions of failures of these systems. For sophisticated analysis it is necessary an effective structure and techniques, a reliable design with the implementation of diagnostic and prognose algorithms. The composition of a hybrid system is made up of continuous and discrete parts, whose monitoring requires the estimation of continuous state variables such as the tracking of discrete states (Wang et al, 2013).

Several studies can arise from a dynamic system of gears, with this we can mention the work of a researcher who, through a bibliographic review study, comments on the importance of reliable recognition of the type of failure and the severity of this failure in gears, because the components are subject to hybrid failures. It also considers that multiple hybrid system failures can occur simultaneously, making fault detection activity by the severity level of behavior challenging (Li et $a l, 2016)$. Another group of researchers demonstrates the importance when it developed the review of several studies on fault detection using artificial intelligence in rotating systems, as it demonstrates reliability and effectiveness for modern industries in different operating situations (Liu 
et al, 2018). Another researcher uses the artificial immune systems of negative selection (AIS) in conjunction with SHM, whose positive results are demonstrated in the analysis and classification of vibration signals, determined by the degree of severity and probability of failures (Outa et al, 2020).

The objective of this work is to analyze, identify and classify the progression of failure growth in a pair of gears, considered a hybrid system, using vibration and acoustic techniques concomitantly with the artificial immune system of negative selection. This work, which is difficult to develop, is divided into: theory; data collect; signal treatment by the Wiener filter; classification and grouping of signals by the artificial immune system.

\section{Hybrid Systems: Gears}

The hybrid system can be understood as a combination of continuous and discrete events, of behavior determined by the interaction between different components, which may or may not have interference from external factors. The factors that led to the formation of this concept are:

- The hybrid system, driven by a paradigm, is a suitable tool that represents a variety of diverse applications in nature;

- Several models of systems and their respective classes are represented by the multimodal concept, such as: multibody mechanical systems, control systems, preypredator systems, and epidemic disease models;

- The asynotic stability of dynamic systems by multiple control laws;

- Minimizing the complexity of analysis in hierarchically sophisticated mechanical systems, using mathematics as an information management tool (Alwan, Liu, 2018; Sworder, Boyd, 2004).

The generalized mathematics of a hybrid system must contain: differential equations that represent the continuous evolution of a process; and/or a finite sequence of dynamic subsystems or switched modes formed by a discrete signal based on a control; and/or different systems result as permutation of action of impulsive actions, and this system may become more complex when the occurrence of time delay and random noises are analyzed (Alwan, Liu, 2018). Basically, hybrid dynamic systems are governed by the combination of continuous and discrete dynamics. Switched systems evolve according to continuous and/or discrete mode-dependent dynamics, with unexpected transitions between modes (Liu, Stechlinski, 2017).

You can exemplify the action of the gear pair as a hybrid system. The gears have the purpose of transmitting the movement (energy) from one rotating shaft to the other, whose action is made considering the contact between two gear teeth until the separation of these (Collins et al, 2010; Vullo, 2020). Figure 1 shows the interference relationship or contact area between the two-gear straight teeth (Collins et al, 2010). 


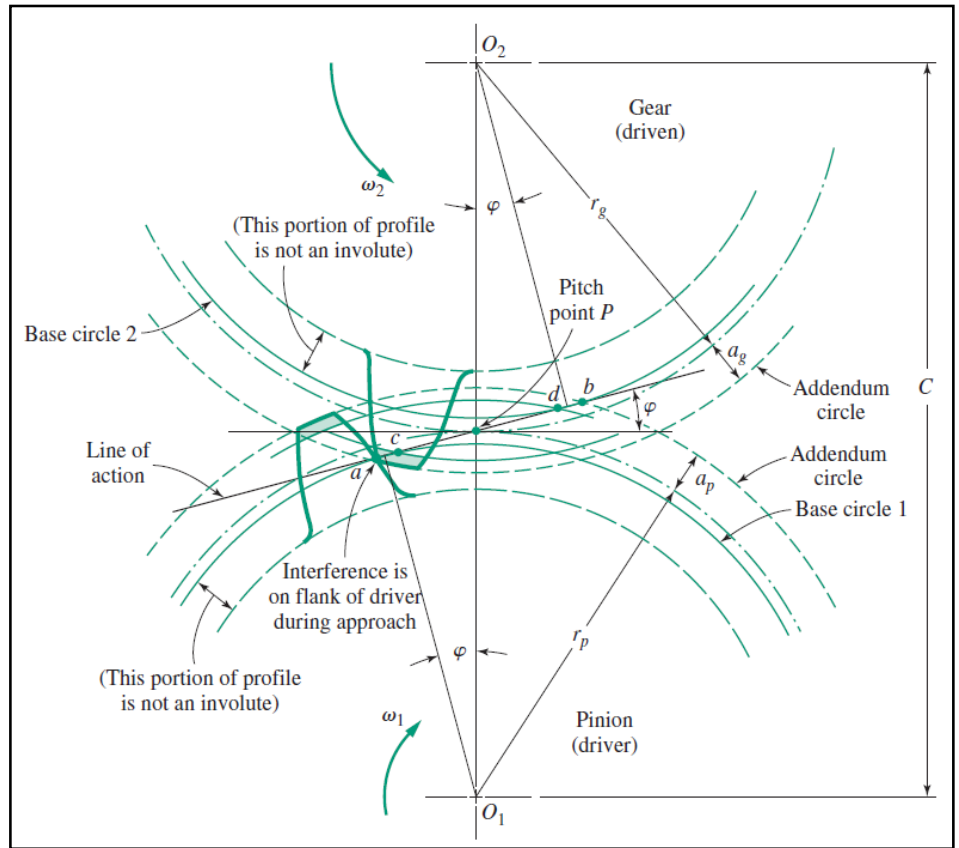

Figure 1 - Interference between pinion-gear teeth

It is noted that the length of action $(\mathrm{Z})$ is considered the distance between the point $\mathrm{a}$ and $\mathrm{b}$, $Z=\sqrt{\left(r_{p}+a_{p}\right)^{2}-\left(r_{p} \cos \varphi\right)^{2}}+\sqrt{\left(r_{g}+a_{g}\right)^{2}-\left(r_{g} \cos \varphi\right)^{2}}-C \sin \varphi$, which, $r_{p}$ the radius of the pinion; $a_{p}$ is the maximum diameter of the head circle minus the radius of the pinion; $r_{g}$ is the radius of the gear moved; $a_{g}$ is the maximum diameter of the head circle minus the radius of the gear moved (Collins et al, 2010; Vullo, 2020).

Gear problems are difficult to find, for the most part they are just noises. When the contact areas between two gears collide, the noise varies according to the force of the system, causing the irradiation of energy throughout the structure. Through continuous and intermittent movement, the noise generated varies in amplitude, direction and position, as the contact area moves axially through the gear step line. Figure 2 shows the schematic design of the amplitude, direction and position of the excitation force in the gear (Smith, 2013).

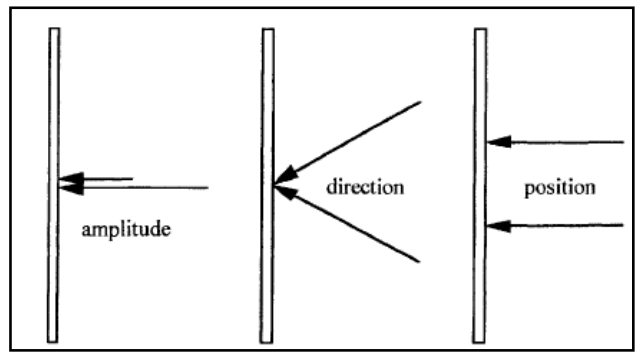

Figure 2 - Excitation Force in relation to Amplitude, Direction and Position

When the gear is triggered several times, the momentary location is positioned differently from the reference location, resulting in the speed change (Palmer, Fish, 2012). This effect results in the transmission error (TE) which is considered the angular difference between the ideal and actual position of the output gear, known as the finite stiffness of gear steaming and the errors of its movement (Vullo, 2020; Park et al, 2018). 
Gear designs are thus considered highly complex, because factors such as the combination of variable loads with surface slips, and external action, directly affect the dynamic system (Collins et $a l, 2010)$. Another phenomenon caused by cyclic repetition are the failures and propagation of cracks along the gear. In this case, the tensile deformation, induced by force in the contact region is directly linked to the stiffness of the surface of the gear teeth (Collins et al, 2010; Vullo, 2020; Smith, 2003).

The hybrid system methodology is used combined with artificial intelligence, because visions of human intelligence are considered as a hybrid system, which contains various types of intelligence. Intelligent computing is composed of a fusion of systems, such as fuzzy logic, neural networks, evolutionary computing. Processing methods, considered as tools for information processing, machine learning, and knowledge representation are known as artificial intelligence (Negoita et al, 2005; Mouchaweh, 2018).

The classification of intelligent hybrid systems is divided into two groups: function-replacing and intercommunicating. Function substitution is a method of combining intelligent computing with artificial intelligence. The intercom method, on the other, is developed to perform a specialized task by applying intelligent computing and the most appropriate artificial intelligence (Mouchaweh, 2018).

\section{Dynamic Systems: Vibration and Acoustics}

A dynamic system is defined as the joint action of the combination of different elements, whose purpose is to perform specific tasks. This dynamic system can be modeled through mathematical equations, usually through linear and nonlinear partial differential equations, the condition of which depends exclusively on the initial conditions and the qualitative model under study (Davies, Schimitz, 2015). For the mathematical solution of a linear system, the principles of aditivity and proportionality between excitation and response are valid (Ogunfunmi, 2007). Basically, nonlinear dynamic systems are considered a system that has no linear behavior and cannot be predetermined due to the randomness of the variables, that is, the system evolves over time with an unbalanced and aperiodic behavior, whose future depends on the initial conditions (Smith, 2007).

Dynamic systems can be analyzed by the principle of vibrations to predict their behavior. Thus, vibrations are phenomena that can be found in many places of nature, some are made by human instruments, others can be found in structures in general. In a way, it is necessary to eliminate unwanted vibrations by reducing or enclosing them. The mathematical models used in vibration theory refer to the characteristics of a physical model under study, which are usually difficult to represent because it involves complex information. Mathematical problems are generally represented by differential equations and solved using software and computer resources (Meirovitch. 2000). The types of excitations in the dynamic system are: excitation in steady state, considered harmonic and periodic excitations; transient excitation, considered non-periodic excitations. With this, dynamic systems represented by second-order equations are considered systems with a degree of freedom - single degree of freedom (SDOF). Figure 3 shows a SDOF massspring-damper (Meirovitch. 2000).

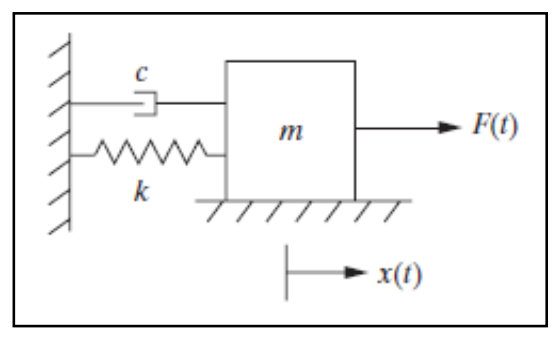

Figure 3 - SDOF mass-spring-damper system 
The general equation representing the SDOF system can be written as,

$m \ddot{x}+c \dot{x}+k x=F(t) \cos (\omega t)$

where, $\mathrm{m}$ is the mass; $\mathrm{c}$ is damping; $\mathrm{k}$ is stiffness; $\mathrm{x}$ is the displacement of the mass; $\dot{\mathrm{x}}$ and $\ddot{\mathrm{x}}$ correspond respectively to the first and second derivative of $x$ in time (Meirovitch. 2000).

The sound wave can be defined as the oscillatory movement of the molecules of a given gaseous or liquid fluid, whose movement begins through fluid compression, together with the variation of pressure. The origin of the sound wave is adverse, and may be from nature, of objects made by the human being, such as the structures and machines that produce vibrations. The sound wave has characteristics of displacement and velocity in particles and are like the behavior of elastic waves in solids (Kinler et al, 1999; Crocker, 2007). The sound or acoustic wave is formed by the concepts: of the equation of states in gases; of the continuity equation; and Euler's equation and can be written as,

$\frac{\partial^{2} \mathrm{p}}{\partial \mathrm{x}^{2}}-\frac{1}{\mathrm{c}^{2}} \frac{\partial^{2} \mathrm{p}}{\partial \mathrm{t}^{2}}=0$

where $\mathrm{p}$ is the pressure in the fluid; $\mathrm{c}$ is the thermodynamic speed of sound (Kinler et al, 1999; Crocker, 2007). The acoustic wave moves considering the fact that a given disturbance is imposed on the random movement of molecules in the fluid (energy transfer between molecules), whose average velocity and molecular interaction increase with the absolute temperature of the gas. With this, the propagation speed of the acoustic wave depends exclusively on the absolute temperature of the gas and not on the intensity of the acoustic wave disturbance (Crocker, 2007). The unidirectional propagation acoustic wave velocity equation can be written as,

$\frac{\mathrm{p}}{\mathrm{u}}=\rho \mathrm{c}$

where $\mathrm{u}$ is the propagation speed of the acoustic wave; $\rho c$ is considered the characteristic impedance of the fluid ( $\rho$ is the density), in the case of air $\rho c=428 \mathrm{~kg} / \mathrm{m}^{2} \mathrm{~s}$ for $0^{\circ} \mathrm{C}$ and $\rho c=415 \mathrm{~kg} / \mathrm{m}^{2} \mathrm{~s}$ for $20^{\circ} \mathrm{C}$; the wavelength is $\lambda=\frac{\mathrm{c}}{\mathrm{f}}$, where $\mathrm{f}$ is the frequency $(\mathrm{Hz})$. The sound intensity of the acoustic wave is $\mathrm{I}=\frac{\mathrm{p}^{2}}{\rho \mathrm{c}}$ (Kinler et al, 1999; Crocker, 2007).

\section{Digital Signal Processing: Wiener Filter}

The signal can be considered a portion of information of a synthetic or natural nature, demonstrated as a function of time. The signals, for the most part, contain unwanted information, so it is necessary to process the signal to extract conflicting information (Hussain et al, 2011). Signal processing is a form of conversion from an analog to digital signal, whose values in the time domain are represented in the form of binaries or bits. This process is called digital signal processing (DSP). Figure 4 shows digital signal processing in different steps (Ingle, Proakis, 2012).

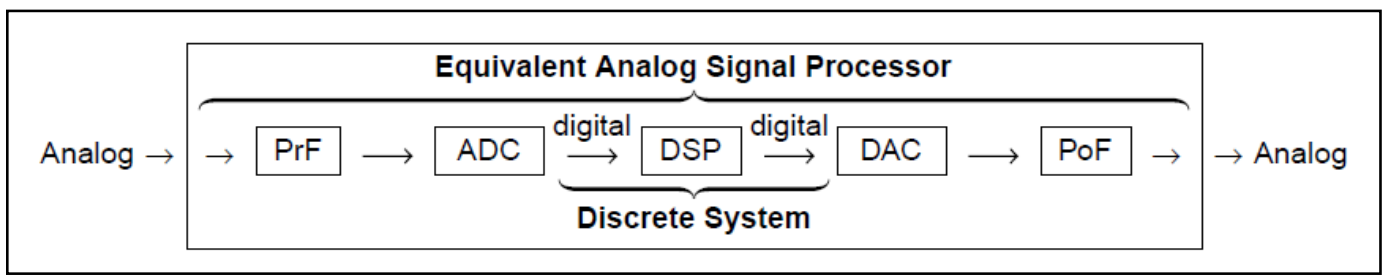

Figure 4 - Digital Signal Processing 
Prf means an antialiasing filter; ADC means an analog to digital converter; The DSP represents a general-purpose computer; The DAC is the digital to analog converter; The PoF is a post-filter that smoothes the waveform (Ingle, Proakis, 2012).

The filter is considered a designed system that extracts noisy data information and can be seen in several areas of engineering. The filtering operation can be divided into three types of processes, being: the filtering process; the smoothing process; and the forecasting process. Filtering is an operation process that involves extracting information about a quantity of interest in the time of the data under analysis. Smoothing is a way to determine an observation between the previous opinion and the information provided by the data under analysis. The forecast tends to obtain information on how the amount of interest will be at some point in the future, using the data under analysis (Haykin , 2014).

The Wiener filter is a mathematical technique that generalizes the integral of convolution, allowing a signal with continuous and one-dimensional noise to be generalized as a discrete signal (Kuo, 1980; Poularikas, Ramadan, 2006).

The mathematical concept of the equation can be written as $\int_{-\infty}^{\infty} g\left(x-x^{\prime}\right) f\left(x^{\prime}\right) d x^{\prime}=f_{0}(x)$, for $-\infty<\mathrm{x}<\infty$, which $\mathrm{f}(\mathrm{x})$ is an unknown function. This function written on the Fourier transform is $F(\alpha)=[G(\alpha)]^{-1} F_{0}(\alpha)$, where $F(\alpha), G(\alpha)$ and $F_{0}(\alpha)$ are Fourier's transforms of $f(x)$, $\mathrm{g}(\mathrm{x})$ and $\mathrm{f}_{0}(\mathrm{x})$, like this, $\mathrm{F}(\alpha)=\mathbb{F}[\mathrm{f}(\mathrm{x}), \mathrm{x}, \mathrm{a}]=\int_{-\infty}^{\infty} \mathrm{f}(\mathrm{x}) \mathrm{e}^{\mathrm{j} \alpha \mathrm{x}} \mathrm{dx} ; \mathrm{G}(\alpha)=\int_{-\infty}^{\infty} \mathrm{g}(\mathrm{x}) \mathrm{e}^{\mathrm{j} \alpha \mathrm{x}} \mathrm{dx}$; $F_{0}(\alpha)=\int_{-\infty}^{\infty} f_{0}(x) e^{j \alpha x} d x$ (Kailath, 1981; Daniele, Zich, 2014).

Wiener integral is rewritten in the semi-infinite domain of 0 to $-\infty, \int_{0}^{-\infty} \mathrm{g}(\mathrm{x}-$ $\left.x^{\prime}\right) f\left(x^{\prime}\right) d x^{\prime}=f_{0}(x)$, where $0<x<\infty$. By rewriting this function as a product of convolution, we will $\int_{-\infty}^{\infty} g\left(x-x^{\prime}\right) f\left(x^{\prime}\right) u\left(x^{\prime}\right) d x^{\prime}=f_{0}(x) u(x)+f_{-}^{s}(x) u(-x)$, which $-\infty<x<\infty$. The $u(x)$ is a step function unit and the function $\mathrm{f}_{-}^{\mathrm{s}}$ is a new unknown that represents the continuation on the left side of the equation, $\int_{-\infty}^{\infty} g\left(x-x^{\prime}\right) f\left(x^{\prime}\right) u\left(x^{\prime}\right) d x^{\prime}$, for $x<0$ (Kailath, 1981; Daniele, Zich, 2014).

The equation in the spectral shape of the Wiener filter function, given the Fourier transform is written as,

$\mathrm{G}(\alpha) \mathrm{F}_{+}(\alpha)=\mathrm{F}_{-}^{\mathrm{s}}(\alpha)+\mathrm{F}_{0+}(\alpha)$

this equation is considered a scalar vector (Daniele, Zich, 2014).

\section{Artificial Immune System (AIS)}

The artificial immune system is based on the biological immune system. Basically, it is an algorithm that deals with biological behaviors using mathematical models capable of replicating certain behaviors.

The algorithm of the artificial immune system of negative selection was applied for the protection of computer systems in the detection of viruses, using the principle of detection and generation of T cells of the immune system. The negative selection algorithm has two distinct steps, the first being censure; the second, monitoring. Censoring generates a set of detectors, where each detector is a string that does not correspond to any of the detected data. The monitoring phase monitors the protected data by comparing it with the detectors, where, in the event of a change a detector is activated (Forrest et al, 1994). Figure 5 shows the flowchart of the censoring and monitoring phase, respectively, on the left and right side (Forrest et al, 1994). 


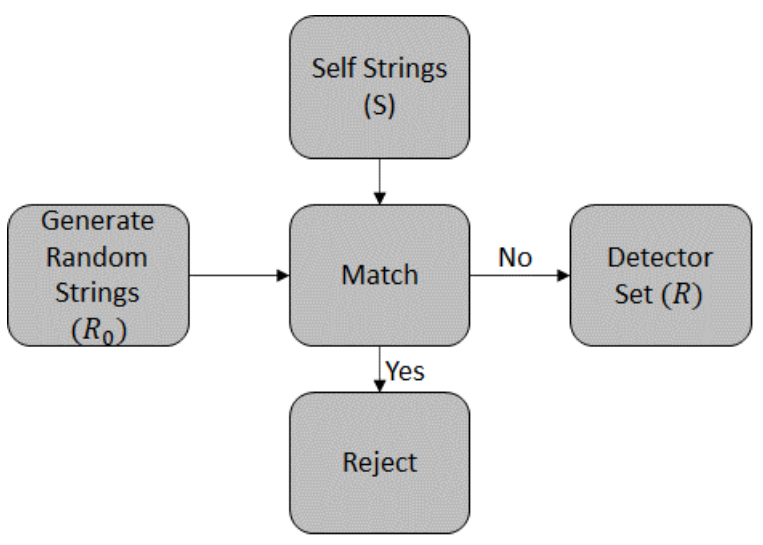

Censoring Step

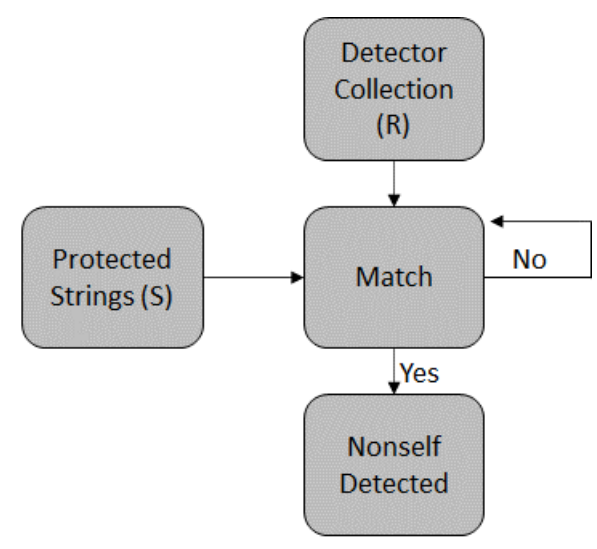

Monitoring Step

Figure 5 - Censoring and Monitoring Steps

The match concept, presented in the censorship and monitoring phase, can be perfect when the match between the two strings of equal sizes with identical symbols occurs. This case is considered extremely rare. The other case occurs when the match is considered partial, and occurs when $r$ close matches, has corresponding symbols and positions, so any two chains $(x, y)$ are matched and considered true when $\mathrm{x}$ and $\mathrm{y}$, correspond at least to $\mathrm{r}$ nearby locations (Forrest et al, 1994). Therefore, the probability of any two $P_{m}$ strings, can be calculated by the equation,

$\mathrm{P}_{\mathrm{m}} \approx\left(\frac{\left(\frac{(1-\mathrm{r})(\mathrm{m}-1)}{\mathrm{m}+1}\right)}{\mathrm{m}^{\mathrm{r}}}\right)$

Note that, l corresponds to the number of symbols in the string (length); m corresponds to the number of symbols of the alphabet; and $\mathrm{r}$ is the next matching number required to match (Forrest $e t$ $a l$, 1994). The affinity rate of $\mathrm{T}_{\mathrm{af}}$ chains, given the proximity match, can be calculated, based on the equation,

$\mathrm{T}_{\mathrm{af}}=\left(\frac{\mathrm{A}_{\mathrm{n}}}{\mathrm{A}_{\mathrm{t}}}\right) 100 \%$

where, $A_{n}$ corresponds to the number of normal chains in the problem, the own strings; and corresponds $A_{t}$ to the total number of chains of the problem, the own and non-own chains (Bradley, Tyrrell, 2002). The quantification of the affinity of the analyzed patterns $\left(Q_{a f}\right)$ should be made considering $\mathrm{Q}_{\mathrm{af}} \geq \mathrm{T}_{\mathrm{af}}$, and can be calculated using the equation,

$\mathrm{Q}_{\mathrm{af}}=\frac{\sum_{\mathrm{i}=1}^{\mathrm{L}} \mathrm{V}_{\mathrm{c}}}{\mathrm{L}} 100 \%$

which $\mathrm{V}_{\mathrm{c}}$ corresponds to the corresponding variables; $\mathrm{L}$ corresponds to the total amount of variables; $\sum_{\mathrm{i}=1}^{\mathrm{L}} \mathrm{V}_{\mathrm{c}}$ corresponds to the sum of the corresponding variables (Lima et al, 2013; Outa el al, 2021). 


\section{Experimental Methodology}

The experiment consists of two gears coupled by right teeth, the source of which is an electric motor that varies speed using a frequency inverter. The main mesh shaft is supported by two bearings, and the coupling gear is supported on a support attached to the structure. Figure 6 shows the coupling between the gears and the shaft support system.

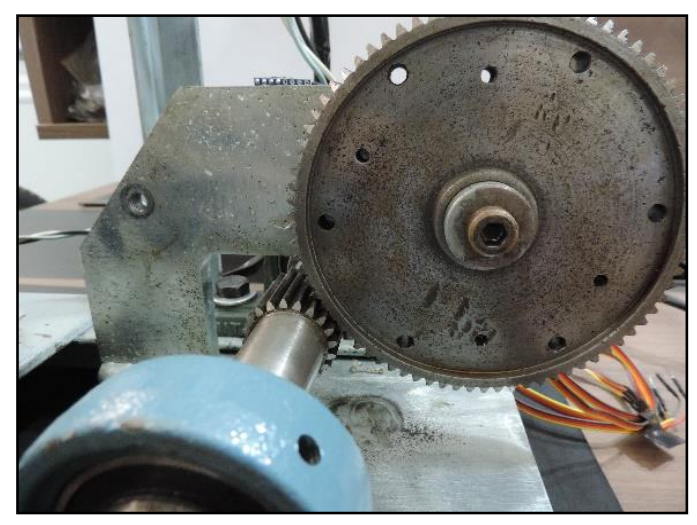

Figure 6 - Rotor with Coupled Gears.

The main shaft movement is made by an electric motor of $0.5 \mathrm{hp}-60 \mathrm{~Hz}$ that has the speed of the motor shaft altered by a CFW 10 - WEG frequency inverter that acts from $0.1 \mathrm{~Hz}$ to $60 \mathrm{~Hz}$. The main shaft is 1045 steel with a diameter of $25.0 \mathrm{~mm}$, the main shaft gear has a maximum tooth height close to $23.0 \mathrm{~mm}$, and the coupling gears have the maximum height of the teeth close to 123.0 $\mathrm{mm}$. The bearings, supporting the main shaft, are both P205 UC205.

The experiment begins with the electric motor at the frequency of $4 \mathrm{~Hz}$, whose vibration and acoustic sensors, connected in the structure, capture the vibration and the noise noise of the shock between the teeth of the gears. This procedure starts with $4 \mathrm{~Hz}$ and extends up to $14 \mathrm{~Hz}$, every $2 \mathrm{~Hz}$. Sample size is 4000 samples. The signal is considered a vector of size $1 \times 4000$. The database of each frequency consists of $51 \times 4000$ size signals. The sensors used in this experiment were: 2 MPU6050 vibration sensors; 1 sound sensor - generic $5 \mathrm{~V}$ electrode microphone $-12 \mathrm{~mm}$ x $22 \mathrm{~mm}$. Figure 7 shows the positioning of the MPU6050 sensors located on the structure and on the bearing.

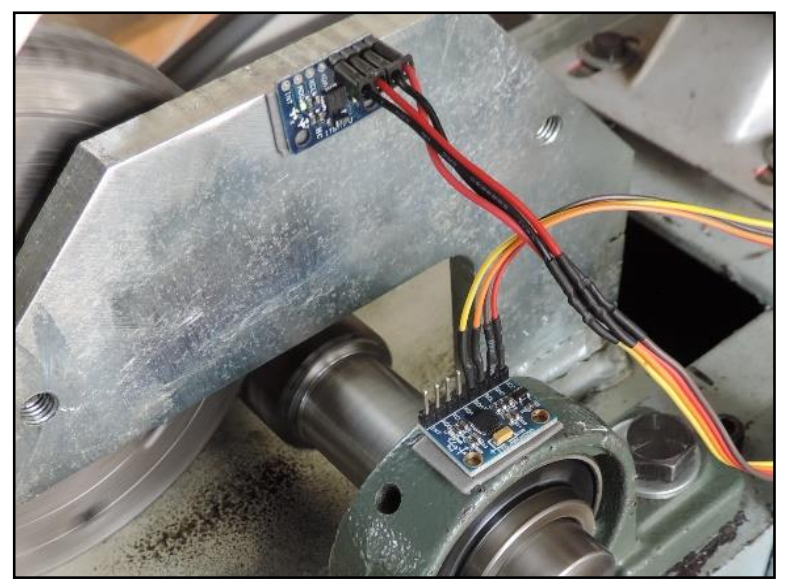

Figure 7 - Positioning the MPU6050 Sensors 
Note that the sensors have been distributed in such a way that the vibration of the support and the bearing can be captured separately, as it is possible that the energy of the main bearing suppresses a part by the high-compensation of the bearing. Figure 8 shows the sound sensor positioned in the structure near the coupling between the gears.

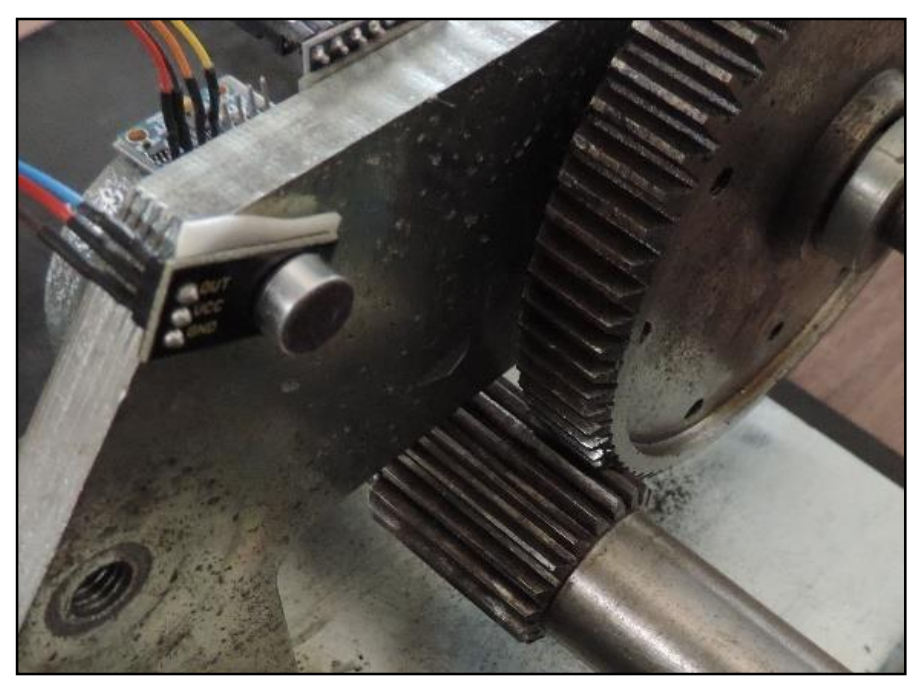

Figure 8 - Positioning of the sound sensor

The distance between the coupled gears and the microphone is ideal enough to collect the signal located consistently. In this case, care was taken considering that the hybrid system, when in operation, emits a noise whose sound pressure of the system is higher than that of the environment. Finally, the result of sound collection can be understood as the sum of sound and ambient pressures. This care should be taken, because if the pressure of the environment without the system noise is greater than that of the system, a wrong context will be analyzed.

The database of size of 4000 samples, for sample validation, was used the finite sample theorem. Using the theorem, the minimum number of samples would be 1111 , considering a sampling error of $2 \%$ and confidence level of $95 \%$. Therefore, it is considered that the 4000 samples can be used safely. The database can be viewed descriptively in table 1.

Table 1 - Database without Filter

\begin{tabular}{ccccc}
\hline \hline Description & Signal & Size & $\begin{array}{c}\text { Total } \\
\text { Signal }\end{array}$ & Frequency \\
\hline \hline $\begin{array}{c}\text { Acoustic sign of acoustic sensor } \\
\text { Mancal sensor vibrating signal } \\
\text { (MPU6050) }\end{array}$ & $1 \times 4000$ & $\begin{array}{c}5 \text { signs of } \\
1 \times 4000\end{array}$ & 30 signs & $4 \mathrm{~Hz} \sim 14 \mathrm{hz}$ \\
$\begin{array}{c}\text { Structure sensor vibration signal } \\
\text { (MPU6050) }\end{array}$ & $1 \times 4000$ & $\begin{array}{c}5 \text { signs of } \\
1 \times 4000\end{array}$ & 30 signs & $4 \mathrm{~Hz} \sim 14 \mathrm{hz}$ \\
\hline \hline
\end{tabular}


The data-Wiener bank corresponds to a total of $901 \times 4000$ size signals. Following the collected signals, these were processed by the Wiener filter, so that the unwanted noise was eliminated. Thus, all signals will be considered as a new database, whose name will be considered as data-Wiener. The next processing is to introduce the concept of the artificial immune system in the data-Wiener of acoustics and vibration, so that the classification and grouping of failures are made.

Figure 04 shows an example of the vibrating signal without the Wiener filter and the vibrating signal after the Wiener filter. Figure 9 shows an example of the vibration signal without the Wiener filter and the vibration signal after the Wiener filter. This signal is the average of the $4 \mathrm{~Hz}$ signal of the bearing.

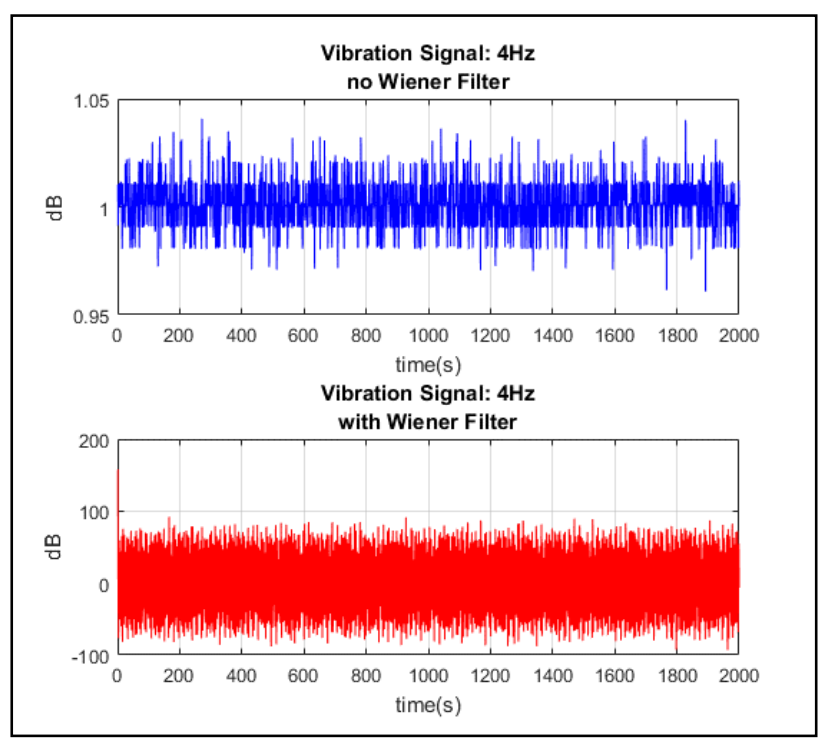

Figure 9 - Vibration Signal without and with Wiener filter

Using the $4 \mathrm{~Hz}$ frequency as reference between the signals, it was possible to demonstrate the evolution of the classification and prognosis of the data-Wiener failures of the vibration and acoustic signal. Thus, the result of the prognosis and classification of failures of the data-Wiener for the frequencies $6 \mathrm{~Hz}, 8 \mathrm{~Hz}, 10 \mathrm{~Hz}, 12 \mathrm{~Hz}$ and $14 \mathrm{~Hz}$ of the bearing; of the support (structure) and the acoustic, can be seen in figures 10,11 and 12 , respectively.

Note that for the $6 \mathrm{~Hz}, 8 \mathrm{~Hz}, 10 \mathrm{~Hz} 12 \mathrm{~Hz}$ and $14 \mathrm{~Hz}$ signals, from the $4 \mathrm{~Hz}$ reference comparison, they demonstrate that the failure classification and prognosis for the bearing vibration, support vibration and acoustic signals, had the same behavior by classifying them. as a type of failure of very high severity level. Considering the same signals as the relative frequencies, the signals form classified as the probability of level 4 failures, which means the probability of very high failure. Thus, level 1 is the probability of low failure; level 2 is the probability of moderate failure; level 3 is the probability of high failure. This experimental condition can be demonstrated through the condition that the signal collected from the $4 \mathrm{~Hz}$ vibration of the bearing and the signal collected from the $4 \mathrm{~Hz}$ acoustic signal, both FRF, have similarity in the frequency domain. Figure 14 shows the FRF of the acoustic signal and the $4 \mathrm{~Hz}$ vibration signal. 

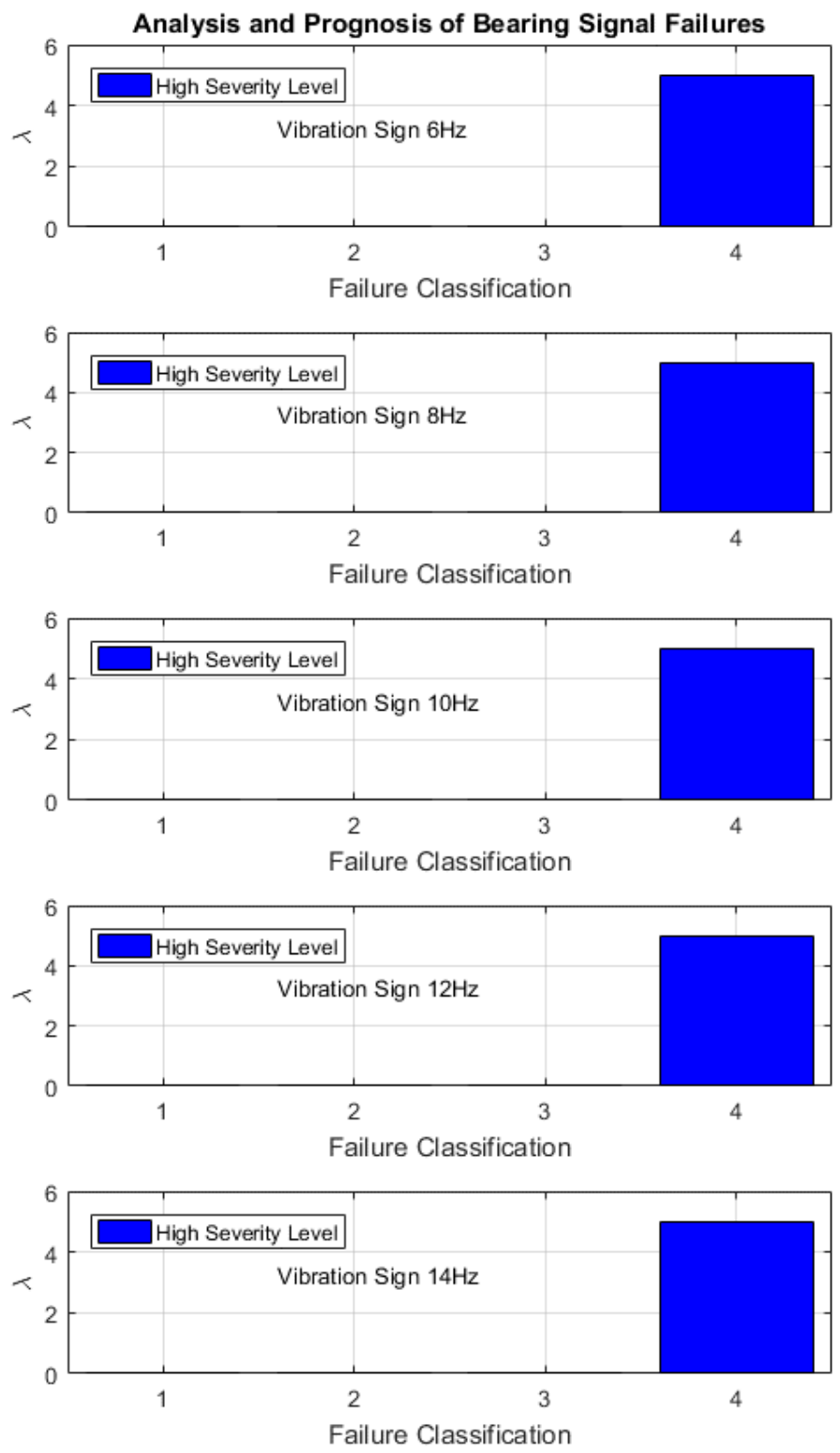

Figure 10 - AIS Analysis - Bearing Data-Wiener. 

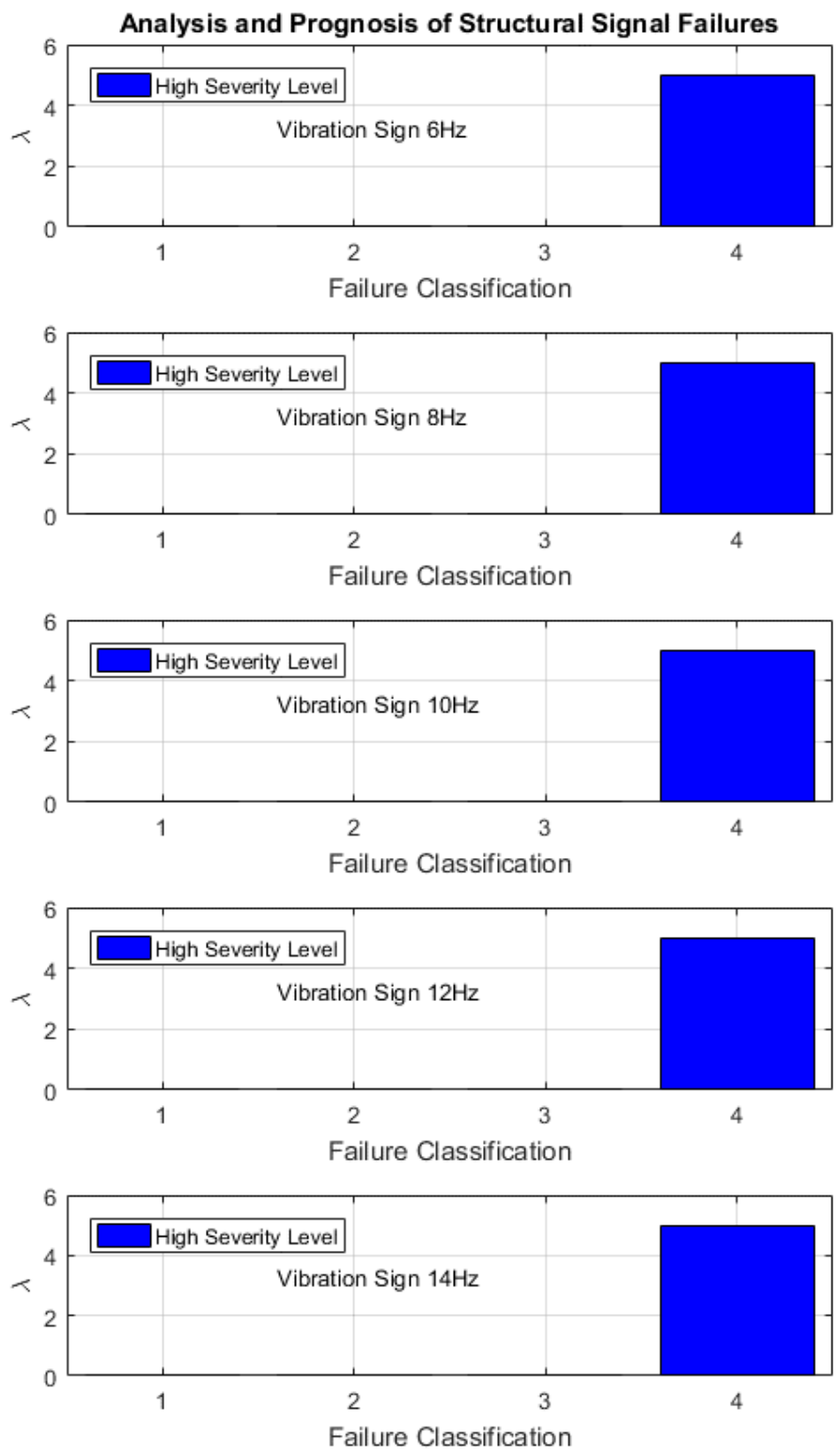

Figure 11 - AIS Analysis - Data-Wiener of the Structure. 

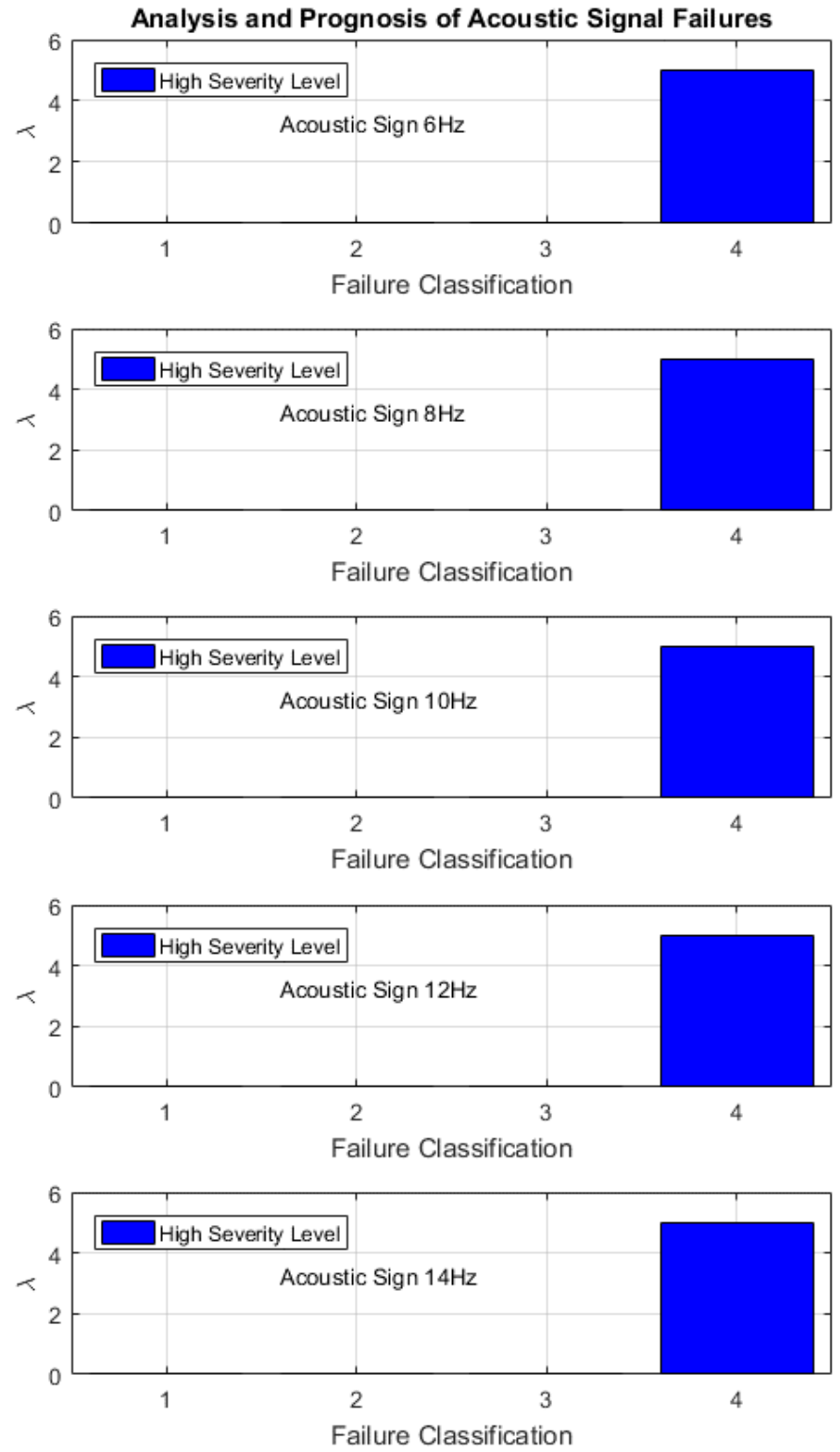

Figure 12 - AIS Analysis - Acoustic Data-Wiener. 


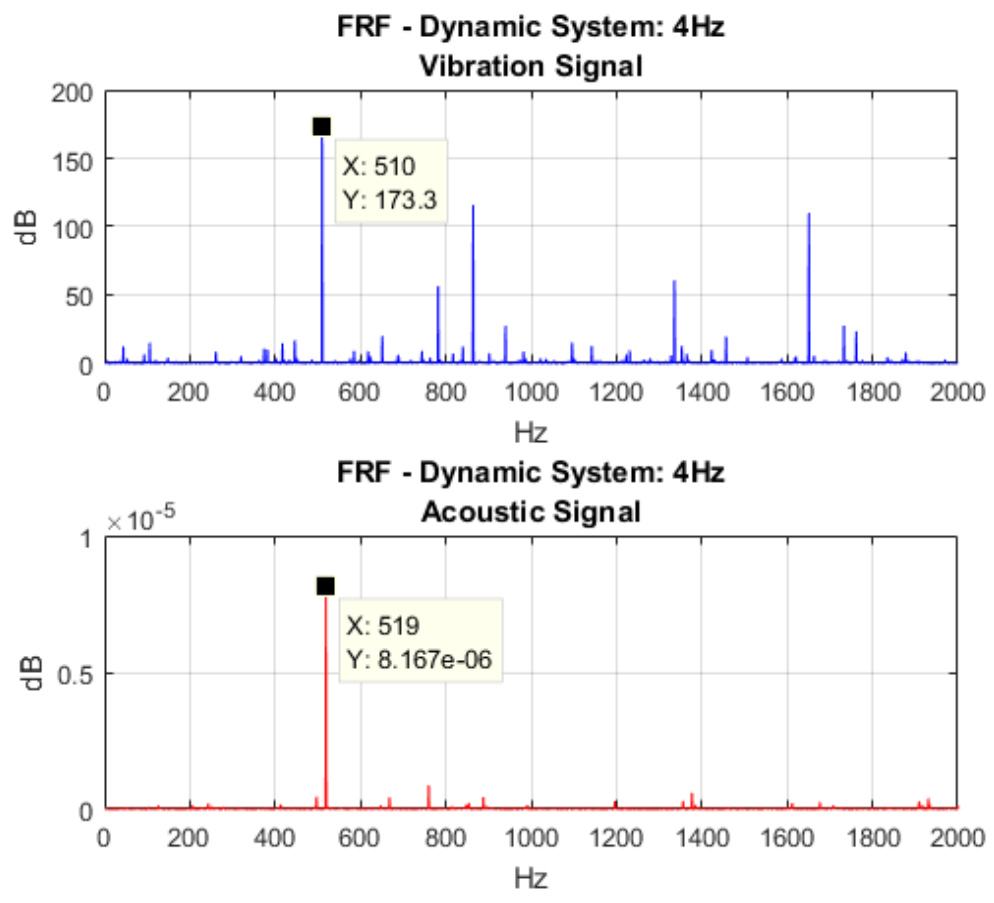

Figure 14 - FRF similarity in the Frequency Domain

Note that the FRF of the vibration signal has a value of $510 \mathrm{~Hz}$, the FRF of the acoustic signal has a value of $519 \mathrm{~Hz}$. Basically, it is possible to state that they are similar, because the difference between frequencies is in the limitation of the experiment. This difference is approximately $1 \%$. Considering the condition of similarity, the technique of analysis and prognosis of failures by the artificial immune system can be considered effective and robust. Figures 15, 16 and 17 represent respectively the evolution of the failures of the bearing signals, the structure signal and the acoustic signal.

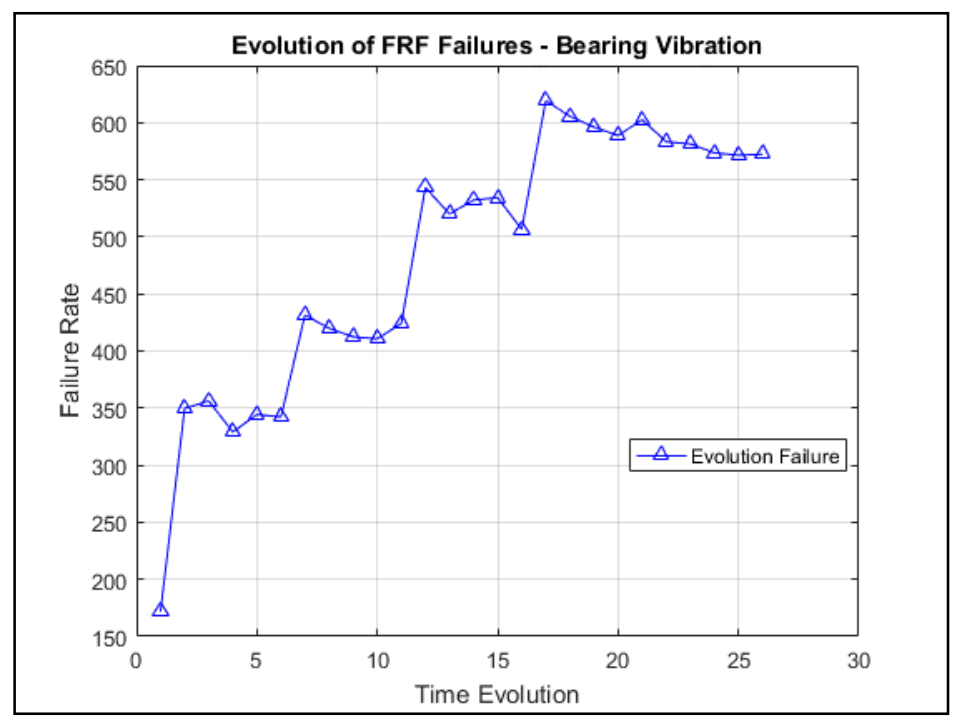

Figure 15 - Evolution of Failures - Bearing 


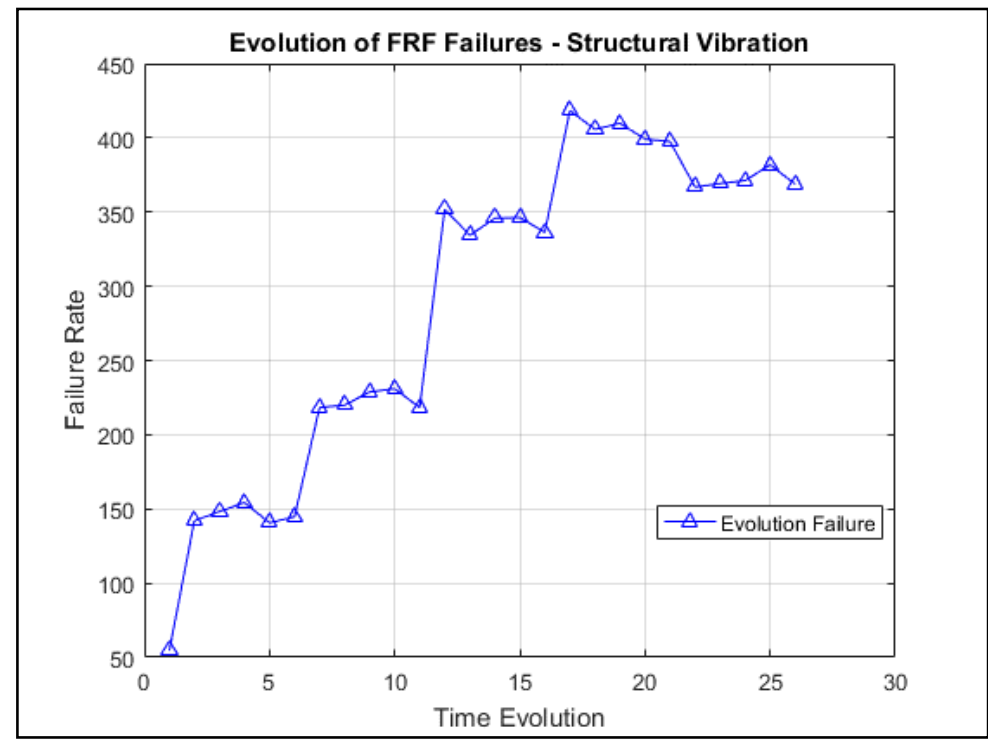

Figure 16 - Evolution of Failures - Structure

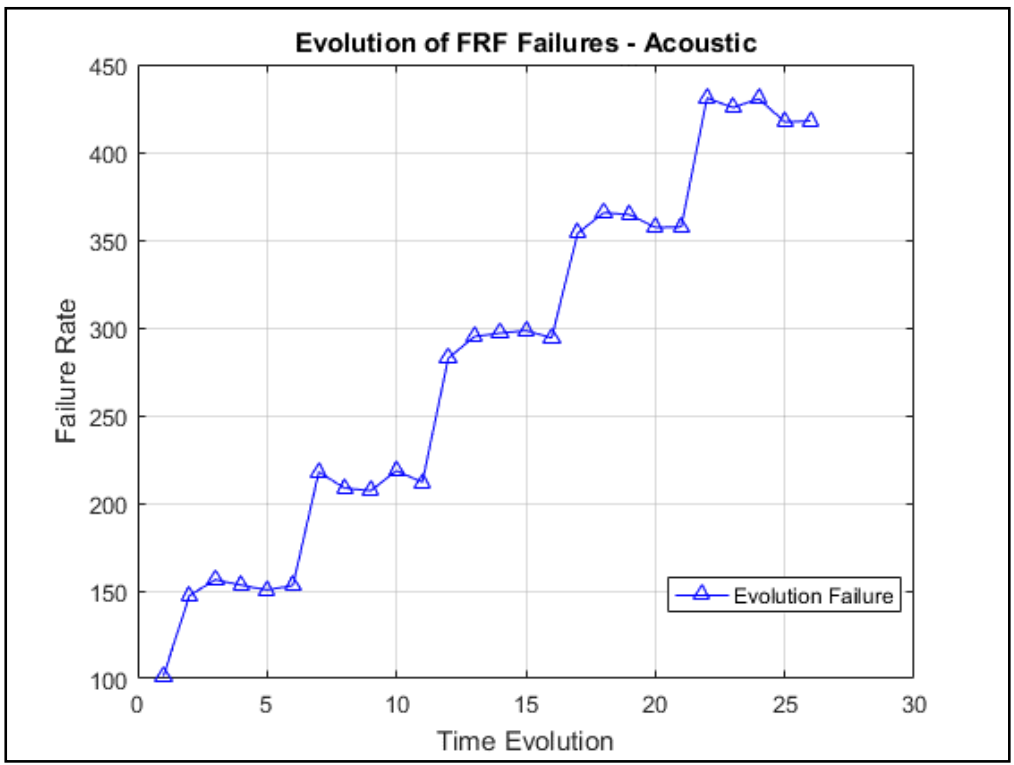

Figure 17 - Evolution of Failures - Acoustic

Note that, in the evolution of the failures of the bearing and support vibration signal, it has the same behavior as the growth curve, showing a small variation in the frequencies of $12 \mathrm{~Hz}$ and $14 \mathrm{~Hz}$. Already analyzing the behavior of the acoustic curve in relation to the vibration curves, it is noted that the frequencies of $12 \mathrm{~Hz}$ and $14 \mathrm{~Hz}$ do not have the same behavior. In this analysis it is possible to affirm that the technique of detection and prognosis of acoustic signal failures may be more precise, considering the evolution of the accentuation of the curve. 


\section{Discussion}

This work is composed of several important phases, because since the use of vibration theories, acoustics, bioengineering, the assembly of the experiment, data collection, Wiener filter applications in the signal, application of the AIS, the result proved to have significance and coherence in prognosis and probability of failures. This work is multidisciplinary and difficult to develop. Figure 18 shows the flowchart developed in this work.

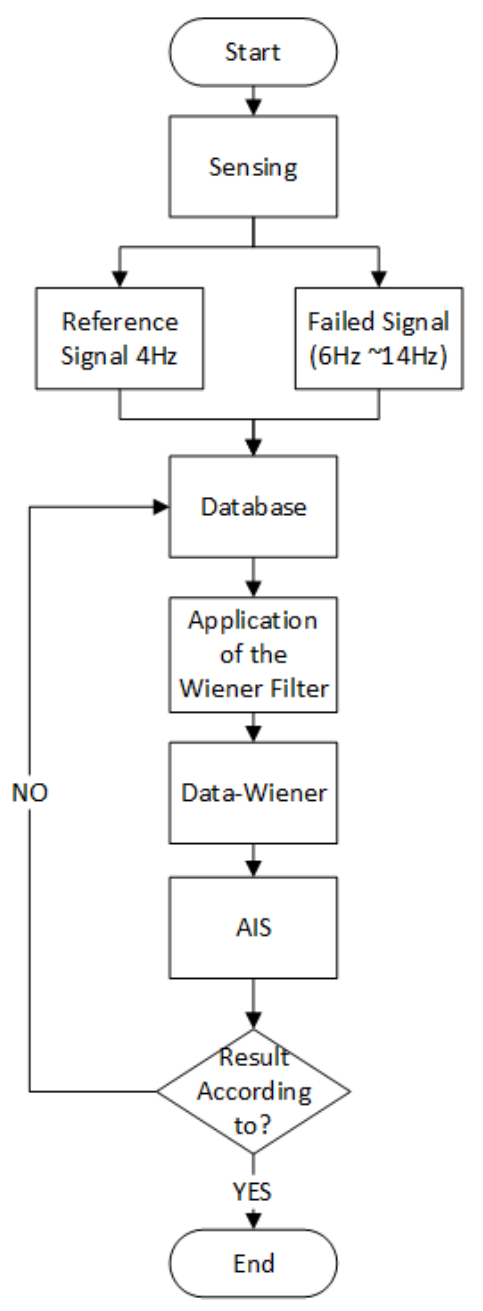

Figure 18 - Work Flowchart

During the development, with the application of the Wiener filter, it was possible to identify the FRFs of the $4 \mathrm{~Hz}$ signal of bearing vibration and acoustics, which is of extreme significance in this work. Thus, it was possible to prove two arguments, the first being that the equal relationship of the probability of failures and the severity level of failures has similarity. In the second argument, the demonstration that, through the growth of the failure curve in the frequencies from $6 \mathrm{~Hz}$ to $14 \mathrm{~Hz}$, some signal analysis frequencies can be studied by the concept of acoustics, which may be more accurate. The main factor in the analysis of the similarity between the FRF's of vibration and acoustic signals demonstrates that both techniques, vibration and acoustics, can be used as reliable methods for the acquisition of signals. 


\section{Conclusion}

According to the positive results demonstrated in this work, it is possible to affirm that the process of using vibration and acoustic techniques has the same level of significance and technical coherence. Another statement is that the technique of artificial immune system of negative selection has relevance and coherence in the analysis, grouping and classification of failures. Therefore, it can be considered as a robust algorithm for the application in this work.

Another relevant factor and positivist view is the use of the Wiener filter for unwanted noise to be eliminated. With this, the analysis of signals becomes more accurate, without the interference of potential errors.

Finally, it can be said that this work has successfully and efficiently achieved its objectives and can even be developed equipment so that, in the near future, they are used in the industry.

\section{Acknowledgments}

The authors thank the Paula Souza Center - CPS for their support and encouragement of research in FATEC's. They also thank the Laboratory of Complex Systems (Sisplexes) of the Institute of Chemistry - UNESP, for allowing work in the physical space, the computer park and the support of the São Paulo Research Foundation (FAPESP) and to the National Council for Scientific and Technological Development (CNPq), through process 312972 / 2019-9.

\section{References}

Alwan, M.S., \& Liu, X., (2018), Theory of Hybrid Systems: Deterministic and Stochastic, Springer Nature Singapore, Beijing.

Bloch, H.P., \& Geitner, F.K., (2012), Machinery Failure Analysis and Troubleshooting: Practical Machinery Management for Process Plants, Elsevier, Oxford.

Borutzky, W. (2021), Bond Graph Modelling for Control, Fault Diagnosis and Failure Prognosis, Springer Nature, Gewerbestrasse.

Bradley, D.W., (2002), Tyrrell, A.M., Immunotronics-novel finite-state-machine architectures with built-in self-test using self-nonself differentiation. IEEE Transactions on Evolutionary Computation, 6, 227238.

Collins, J.A., Busby, H.R., \& Staab, G.H., (2010), Mechanical Design Of Machine Elements And Machines: A Failure Prevention Perspective, John Wiley \& Sons, Hoboken.

Crocker, M. J. (2007), Handbook of noise and vibration control. Hoboken: John Wiley \& Sons.

Daniele, V.G., \& Zich, R.S., (2014), The Wiener-Hopf Method in Electromagnetics, Edison, SciTech Publishing.

Davies, M.A., \& Schimitz T.L., (2015), System Dynamic for Mechanical Engineers, Springer Science+Business Media New York

Echeberria, A.L. (2020). A Digital Framework for Industry 4.0: Managing Strategy, Springer Nature, Gewerbestrasse.

Forrest, S., Perelson, A.S., Allen, L., \& Cheukuri, R., (1994), Self-Nonself Discrimination in a Computer, IEEE Computer Society Symposium on Research in Security and Privacy, DOI: https://doi.org/10.1109/RISP.1994.296580.

Haykin, S., (2014), Adaptive Filter Theory, Pearson Education, Saffron House.

Hermann, M., Pentek, T., \& Otto, B. (2016). Design principles for industrie 4.0 scenarios. In: Hawaii International Conference on Systems Science. 2016. p. 3928-3937.

Hussain, Z.M., Sadik, A.Z., \& O’Shea, P., (2011), Digital Signal Processing: An Introduction with MATLAB and Applications, Springer-Verlag, Heidelberg.

Ingle, V.K., \& Proakis, J.G., (2012), Digital Signal Processing Using MATLAB, Cengage Learning, Stamford.

Kagermann, H., Wahlster, \& W., Helbig, J. (2013). Securing the future of German manufacturing industry: Recommendations for implementing the strategic initiative Industrie 4.0. Frankfurt.

Kailath, T., (1981), Lectures on Wiener and Kalman Filtering, Wien, Springer-Verlag. 
Kinsler, L. E., Frey, A. R., Coppens, A. B., \& Sanders, J. V., (1999), Fundamentals of acoustics. Hoboken: John Wiley \& Sons.

Kuo, H.L., (1980), A More Generalized Wiener Filtering Technique, IFAC Proceedings Volumes, 13(11), 539-542.

Li, Z., Jiang, Y, Hu, C., \& Peng, Z., (2016), Recent progress on decoupling diagnosis of hybrid failures in gear transmission systems using vibration sensor signal: A review. Measurement, 90(1), 4-19. DOI: https://doi.org/10.1016/j.measurement.2016.04.036.

Lima, F.P.A., Lotufo, A.D.P., \& Minussi, C.R., (2013), Artificial Immune Systems Applied to Voltage Disturbance Diagnosis in Distribution Electrical Systems, Proceedings on IEEE PowerTech-2013, DOI: https://doi.org/10.1109/PTC.2013.6652127.

Liu, R., Yang, B., Zio, E., \& Chen, X., (2018), Artificial intelligence for fault diagnosis of rotating machinery: A review. Mechanical Systems and Signal Processing, 108(1), 33-47. DOI: https://doi.org/10.1016/j.ymssp.2018.02.016.

Liu, X., \& Stechlinski, P., (2017), Infectious Disease Modeling: A Hybrid System Approach, Springer International Publishing, Gewerbestrasse.

Meirovitch, L., (2000), Principles and Techniques of Vibrations, Prentice Hall, New Jersey.

Mouchaweh, M.S., (2018), Diagnosability, Security and Safety of Hybrid Dynamic and Cyber-Physical Systems, Springer International Publishing, Gewerbestrasse.

Negoita, M., Neagu, D., \& Palade, V., (2005), Computational Intelligence: Engineering of Hybrid Systems, Springer-Verlag, Heidelberg.

Ogunfunmi, T., (2007), Adaptive Nonlinear System Identification: The Volterra and Wiener Model Approaches, Springer Science, New York.

Outa, R., Chavarette, F.R., Mishra, V.N, Goncalves, A.C., Roefero, L.G.P., \& Moro, T.C., (2020), Prognosis and fail detection in a dynamic rotor using artificial immunological system. Engineering Computations, 37(9), 3127-3145, DOI: https://doi.org/10.1108/EC-08-2019-0351.

Outa, R.; Chavarette, F.R.; Toro, P.F., Goncalves, A.C., \& Santos, L.H., (2021), Prognosis and Detection of Experimental Failures in Open Field Diesel Engines Applying Wieners Artificial Immunological Systems. Journal of Applied and Computational Mechanics, 7, 1-12. DOI: https://doi.org/10.22055/JACM.2020.34972.2525.

Palmer, D., \& Fish, M., (2012), Evaluation of Methods or Calculating Effects of Tip Relief on Transmission Error, Noise and Stress in Loaded Spur Gears, Gear Technology.

Park. S., Kim, S., \& Choi, J., (2018), Gear Fault Diagnosis Using Transmission Error And Ensemble Empirical Mode Decomposition, Mechanical Systems and Signal Processing, 108(1), 262-275. DOI. https://doi.org/10.1016/j.ymssp.2018.02.028.

Poularikas, A.D., \& Ramadan, Z.M., (2006), Adaptive Filtering Primer with Matlab, Boca Raton, CRC Press. Smith, J.D., (2003), Gear Noise and Vibration, Marcel Dekker, New York.

Smith, L. A., (2007), Chaos, A Very Short Introduction, Oxford University Press, Great Clarendon Street, Oxford ox 2 6dp, New York.

Sworder, D.D., \& Boyd, J.E., (2004), Estimation Problems in Hybrid Systems, Cambridge University Press, Cambridge.

Vullo, V., (2020), Gears: Geometric and Kinematic Design, Springer Nature, Switzerland.

Wang, D., Yu, M., Low, C.B., \& Aroget, S., (2013) Model-based Health Monitoring of Hybrid Systems, Springer Science, New York. 